\title{
Benefit of Tympanoplasty with or without Cortical Mastoidectomy in Active Mucosal Otitis Media - A Comparative Study
}

\author{
Anushree Raviprakash Bajaj, ${ }^{1}$ Shahnaz Sheikh, ${ }^{1}$ Samir Joshi, ${ }^{2}$ Bhalchandra Paike ${ }^{1}$
}

\begin{abstract}
Introduction
$\underline{\text { ABSTRACT }}$

Chronic otitis media (COM) is amongst the most common diseases treated by ENT surgeons in India. It has been advocated in lot of research articles that there is no significant difference in tympanoplasty done in active and inactive COM. The objective was to see if cortical mastoidectomy in cases of active mucosal COM, improves the success rate of tympanoplasty measured as per the following parameters: improvement in the hearing threshold by $15 \mathrm{~dB}$, increased graft uptake and reduction in retraction of tympanic membrane in post operative period.

Materials and Methods

This study comprises of 120 patients coming to the ENT OPD from October 2016 to October 2017 with active mucosal COM with central perforation requiring tympanoplasty. These patients were randomly assigned to two groups: Group 1 of 60 subjects in which tympanoplasty without mastoidectomy was done, Group 2 of 60 subjects in which tympanoplasty with mastoidectomy was done. Patients were evaluated after a post operative period of 3 months.

$\underline{\text { Results }}$

The Results were the hearing improvement was $73.33 \%$ in group 1 while $83.33 \%$ in group 2, graft uptake was $63.33 \%$ in group 1 and $80 \%$ in group 2, graft retraction was 33.33\% and $23.33 \%$ in group 1 and group 2 respectively.

Conclusion

There was statistically significant difference in results in group with and without mastoidectomy in active mucosal chronic otitis media with respect to graft uptake and improved hearing.

$\underline{\text { Keywords }}$

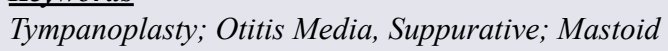

$\mathrm{C}$ hronic Otitis Media (COM) is defined as chronic infection confined to the middle ear mucosal cleft which comprises the eustachian tube, mesotympanum, aditus and mastoid air cells. Clinically, there are two varieties of COM, mucosal and squamous. Chronic suppurative otitis media is amongst the most common diseases for the patients coming to ENT surgeons in India. Tympanoplasty is thus one of the routinely performed surgeries by the ENT surgeons. It is a commonpractice among the otolaryngologists to usually wait for the ear to become inactive before performing tympanoplasty. However, a lot of research papers have been published suggesting no added advantage of an inactive ear over an active ear for better results of the surgical procedure. ${ }^{1,2,3}$
Cortical mastoidectomy is generally performed in mucosal COM to clear the atticoantral block, if present, and achieve aeration of the mastoid. Aeration of the mastoid has been believed to be one of the very important factors in achieving better results of tympanoplasty in terms of graft uptake and hearing improvement. The use of mastoidectomy as a means to re-establish drainage

1 - Department of ENT, Dr Ulhas Patil Medical College, Jalgaon Khurd, Nasik, Maharashtra

2 - Department of ENT, BJ Medical College and Sasson Hospital, Pune, Maharashtra

Corresponding author:

Dr Anushree Raviprakash Bajaj

email: bajajanushree@yahoo.co.in 
of mastoid antrum in safe or non-cholesteatomatous chronic suppurative otitis media is still controversial. ${ }^{4}$

This study was designed to assess the effectiveness of cortical mastoidectomy in cases of active mucosal COM. We wanted to evaluate if aerating the mastoid by simple cortical mastoidectomy in cases of active mucosal COM improves the success rate of tympanoplasty measured as per the following parameters: Improvement in the hearing threshold by $15 \mathrm{~dB}$ measured by pure tone audiometry,increased graft uptake and reduction in retraction of tympanic membrane in post-operative period.

\section{Materials and Methods}

This study comprised 120 patients coming to the ENT OPD from Oct. 2016 to Oct. 2017 with active mucosal $\mathrm{COM}$ and central perforation requiring tympanoplasty. These patients were randomly assigned to two groups by simple randomization method - Group 1 of 60 subjects in which tympanoplasty without mastoidectomy was done and Group 2 of 60 subjects in which tympanoplasty with mastoidectomy was done. All the patients were provided with thorough explanations about both the surgical techniques and signed an informed consent before enteringthe study. The patients were explained about the risk involved in operating in active disease and risks involved in doing cortical mastoidectomy.

\section{Inclusion criteria:}

Patients with active or wet ear

Moderate, large, subtotal central perforation

Age more than 14 years

Unilateral or bilateral disease

\section{Exclusion criteria:}

Patients having otomycosis

\section{Revision surgery}

Patients having focal infective sources like nose and paranasal sinuses infection, DNS,tonsillitis etc.

Patients refusing consent to be included in the study

All the patients underwent routine ENT and preanaesthetic evaluation. Puretone audiometry and impedance audiometry were conducted in all patients in preoperative and postoperative periods(after 3 months).
Eustachian tube functional assessment was done using Toynbee test (impedance audiometry). Suction clearance and otoscopic findings were confirmed under microscope. Discharge was sent for culture and sensitivity. X-ray mastoids were taken in both groups.

Surgery was done under local or general anaesthesia as per the convenience of the patient, using postaural incision and underlay technique. In Group 1, tympanoplasty without mastoidectomy was undertaken and in Group 2, tympanoplasty with cortical mastoidectomy was done along with widening of the aditus and antrum. Thorough removal of the mastoid cells was attempted to reduce the air cells that could act as infection nidus. Type of tympanoplasty was type 1 or type 3 with or without ossiculoplasty depending on intra operative finding and pre-operative hearing threshold. Temporalis fascia graft was used. Sutures were removed on the 7 th day post-operatively.

In the postoperative period assessment of the graft was done - overall uptake of graft ( $100 \%$ or not) after 3 months, hearing threshold by pure tone audiometry after 3 months and retraction of the tympanic membrane(present or not) using impedance audiometry after 3 months.Data regarding the preoperative work up, operative technique and assessment during follow-up were entered in a specially prepared proforma.

\section{Results}

A comparative surgical evaluation study was done consisting of 120 patients of active mucosal COM,60 underwent tympanoplasty without mastoidectomy, while another 60 underwent tympanoplasty with mastoidectomy.

In our study $46 \%$ individuals were in the age group of 14-30 years and 31-50 years respectively in Group 1 , while $43 \%$ and $50 \%$ were in the above age group in Group 2. Patients above the age of 50 years comprised $2.8 \%$ in both the groups. The male patients were 36 and 38 in Groups 1 and 2 respectively while female patients were 24 and 22 in Group 1 and 2 respectively. The male to female ratio was 3:2 in Group 1 and 3.2:1 in Group 2. The ratio of unilateral to bilateral was $2.75: 1$ in Group 1 , while 3.28:1 in Group 2. The size of perforation in 
Table I: Preoperative hearing threshold

\begin{tabular}{|c|c|c|}
\hline PREOP HEARING & GROUP 1 & GROUP 2 \\
\hline$<20 \mathrm{~dB}$ & - & - \\
\hline $20-35 \mathrm{~dB}$ & 38 & 36 \\
\hline $36-50 \mathrm{~dB}$ & 14 & 20 \\
\hline$>50 \mathrm{~dB}$ & 8 & 4 \\
\hline Total & 60 & 60 \\
\hline
\end{tabular}

Group 1 was 26 moderate, 24 large and 10 subtotal while in Group 2 was 32 moderate, 16 large and 12 subtotal. The percentage of moderate, large and subtotal perforation in Group 1 was $43.33 \%, 40 \%, 16.66 \%$ and in Group 2 was $53.33 \%, 26.66 \%, 20 \%$ respectively. The preoperative hearing threshold was between $20-35 \mathrm{~dB}$ in Group 1 and 2 was $63.3 \%$ and $60 \%$. (Table I)

The patients in both the groups underwent type 1 and type 3 tympanoplasty.

The percentage of patients who underwent type 1 tympanoplasty was $70 \%$ and $73.33 \%$, while those who underwent type 3 tympanoplasty was $23.33 \%$ and $26.66 \%$ respectively in Group 1 and Group 2. The improvement in the hearing threshold was $73.33 \%$ in Group 1 and $83.33 \%$ in group 2. (Table II)

The postoperative graft uptake was $63.33 \%$ in Group 1 and $80 \%$ in Group 2. (Table III) The post operative retraction was present in $33.33 \%$ in Group 1 and $23.33 \%$ in Group 2. (Table IV)

In the patients with bilateral disease graft uptake in Group 1 was $62.5 \%$ and in Group 2 was $85.71 \%$,while hearing improvement was $62.5 \%$ in Group 1 and $85.7 \%$ in Group 2. (Table V)

\section{Discussion}

This is a study of 120 patients in which 120 ear surgeries were performed with age greater than 14 years. Eighty percent patients belonged to lower socioeconomic status, $15 \%$ were in middle economic strata while $5 \%$ belonged to upper socioeconomic strata.

Temporalis fascia was used as graft material in both the groups. Of all the graft materials, temporalis fascia has become most popular and standard to which all others are compared. ${ }^{5}$ Patients underwent type 1 or type 3 tympanoplasty (with or without ossiculoplasty) depending on the preoperative hearing loss and intraoperative finding. Patients were evaluated after a postoperative period of 3 months. Post-operative assessment was done under the following parameters: Hearing threshold, Graft uptake and Presence of retraction.

In our study mean age was 35.3 and 32.8 years in Group 1 and Group 2 respectively. Age of the patients was not found to have any direct effect on the postoperative results. According to Adkin et al, age has no significant bearing on success. ${ }^{6}$ Similarly Emmet studied 260 cases and concluded in his study that age is not a factor in success or failure of healing following tympanoplasty. ${ }^{\text {? }}$

The post-operative result was analysed under the following parameters -1) Assessment of the hearing threshold: After postoperative period of 3 months, improvement in the hearing threshold of greater than $15 \mathrm{~dB}$ was observed in $73.33 \%$ in Group 1, while $83.33 \%$ patients in Group 2 showed improvement.Thus improvement in the hearing threshold of greater than $15 \mathrm{~dB}$ was more in patients in which tympanoplasty was done with mastoidectomy. The difference between the two was statistically significant. Balyan et al, in their study on of 323 patients, observed no statistically significant difference in hearing outcome between those who underwent type 1 tympanoplasty with or without mastoidectomy. ${ }^{8}$ In the study by Mishiro et al the rate of post-operative air bone gap within $20 \mathrm{~dB}$ were $81.6 \%$ in group with mastoidectomy and $90.4 \%$ in group without mastoidectomy without a statistically significant difference. ${ }^{9}$ In another study on 120 subjects, hearing gain was $75 \%$ of subjects in both the groups. This study concluded that it might be a good practice to open the mastoid antrum and the air cells if the middle ear mucosa was unhealthy. ${ }^{10}$ Some other studies reported varying results. ${ }^{11,12,13}$ Nayak et al reported better hearing gain with concomitant cortical mastoidectomy with myringoplasty and a higher success rate as compared to myringoplasty alone. ${ }^{14}$ But all these studies were 
Table II: Postoperative hearing improvement

\begin{tabular}{|c|c|c|c|c|}
\hline $\begin{array}{c}\text { POST OPERATIVE HEARING } \\
\text { IMPROVEMENT }\end{array}$ & GROUP 1 & GROUP 2 & CHI SQUARE & P \\
\hline Improved(>15 dB ) & 44 & 50 & 1.76 & 0.184 \\
\hline Not improved & 16 & 10 & & \\
\hline Total & 60 & 60 & & \\
\hline
\end{tabular}

Table III: Postoperative graft uptake

\begin{tabular}{|c|c|c|c|c|}
\hline GRAFT UPTAKE & GROUP 1 & GROUP2 & CHI SQUARE & P \\
\hline Uptake & 38 & 48 & 4.1 & 0.043 \\
\hline Failure & 22 & 12 & & \\
\hline Total & 60 & 60 & & \\
\hline
\end{tabular}

Table IV: Postoperative retraction

\begin{tabular}{|c|c|c|c|c|}
\hline $\begin{array}{c}\text { POST OPERATIVE } \\
\text { RETRACTION }\end{array}$ & GROUP 1 & GROUP 2 & CHI SQUARE & P \\
\hline Absent & 40 & 46 & 1.47 & 0.22 \\
\hline Present & 20 & 14 & & \\
\hline Total & 60 & 60 & & \\
\hline
\end{tabular}

Table V: Bilateral disease assessment

\begin{tabular}{|c|c|c|c|c|}
\hline BILATERAL DISEASE & GROUP 1 & GROUP 2 & CHI SQUARE & P \\
\hline Graft uptake & $10 / 16$ & $12 / 14$ & 2.05 & 0.15 \\
\hline Hearing improvement & $10 / 16$ & $12 / 14$ & 2.05 & 0.15 \\
\hline
\end{tabular}

undertaken in wet and/or dry ear. In our study with wet active discharging ear, we found that there were better results in cases in which cortical mastoidectomy was done although the difference was not statistically significant.

Assessment of graft uptake was undertaken after postoperative period of 3 months. The overall graft uptake was found to be $63.33 \%$ in Group 1 and $80 \%$ in Group 2. Thus, graft uptake was $15 \%$ better in patients in which tympanoplasty was done with mastoidectomy. However the difference between the two was not statistically significant. Balyan et al found no statistically 
significant difference in graft take rate in Tympanoplasty with or without mastoidectomy. Thus he concluded that aerating the mastoid may improve the success rate of the surgery in revision cases. ${ }^{8}$ In the study by McGrew et al on 484 patients of untreated tympanic membrane perforations, the adjusted rate of subsequent procedures were $15.5 \%$ in Tympanoplasty group and $12.2 \%$ in Tympanoplasty with mastoidectomy group respectively. They concluded that mastoidectomy was not necessary for successful repair of the tympanic membrane. ${ }^{15}$ Similarly Mishiro et al reported graft uptake rate of $90.5 \%$ in Tympanoplasty with mastoidectomy and 93.3\% in Tympanoplasty without mastoidectomy. ${ }^{9}$ Krishnan et al found $82.5 \%$ graft uptake was in patients with Tympanoplasty without mastoidectomy and $100 \%$ in patients with tympanoplasty and mastoidectomy. ${ }^{10}$ Bhatt et al also concluded that there was no statistical difference in groups with or without mastoidectomy. ${ }^{11}$ Thus, tympanomastoidectomy was not found to be superior to Tympanoplasty over short term followup. ${ }^{12,13,16}$

In a 6 month follow-up study, $100 \%$ graft uptake was reported in patients with Tympanoplasty with mastoidectomy and $60 \%$ in patients with tympanoplasty without mastoidectomy. ${ }^{14}$ This study suggested that in small and sclerosed mastoid, it is desirable to do cortical mastoidectomy even if the ear is dry to create a mastoid air reservoir which probably can buffer the detrimental effects of a poorly functioning Eustachian tube. This view was also expounded by Jackler and Schindler in a previous article. ${ }^{17}$ They found the results to be logical and opined that the surgeries by well-trained surgeons over certain durations of time may possibly give better results in group $2 .{ }^{17}$ However, in our study with active discharging ear, there were $15 \%$ better results in group in which Tympanoplasty with mastoidectomy was done.

Assessment of graft retraction after post-operative period of 3 months: Retraction of the tympanic membrane was found to be $33.33 \%$ in group 1 while $23.33 \%$ in group 2 . Thus, the retraction of the tympanic membrane was noted to be $10 \%$ more in group in which Tympanoplasty was done without mastoidectomy; however, the difference between the two was not statistically significant. Wehrs and Tulsa thought that aeration of mastoidectomy cavity was important to prevent retraction pockets and ensured an adequate air reserve. ${ }^{18}$ In the study by Krishnan et al, $20 \%$ of the patients in dry ear group developed retraction of the tympanic membrane after tympanoplasty without mastoidectomy. ${ }^{10}$ Blockade of the aditus to antrum was found in 18 cases out of 30 in Group 2. The postoperative hearing outcome and graft uptake was better in group 2 by $10 \%$ and $15 \%$ than in group 1 .

In our study, the patients with bilateral disease had slightly less success rate than unilateral disease in both Group 1 and Group2. Graft uptake and hearing improvement was $62.5 \%$ and $85.71 \%$ in Group 1 and 2 respectively. Group 2 had 23\% better results than Group 1. The reason for this may be creation of a better reservoir of air by mastoidectomy. Bilateral disease represents a common persistent and severe pathology like eustachian tube blockade, dysfunction and allergy. Hence bilateral disease has been hypothesized to have worse outcome. Albu et al, Pinar et al and Albera et al also reported that patient with contralateral ear disease were associated with lower success rate. ${ }^{16,19,20}$ Ashok et al found lower success rate $(66 \%)$ in presence of bilateral perforation. ${ }^{21}$

In our study the graft uptake for moderate, large and subtotal perforation was $79.31 \%, 75.00 \%$ and $63.63 \%$ respectively. Thus post operative results, related to the size of the perforation, were better in smaller sized perforations. In the study by Adkins et al, there was a definite relationship between the size of perforation and likelihood of success. ${ }^{6}$ There is still a controversy as to whether the size influences the success rate. According to Webb et al, perforation size $(\mathrm{p}=0.11)$ was not significantly related to success rate. ${ }^{12}$ Some other studies also could not relate the success rate of tympanoplasty with tympanic membrane perforation size. ${ }^{16,19,20}$ With increased technical difficulty and larger area, which must vascularise and epithelialize with bigger perforation, surgical failure would not seem unexpected.

Thus with respect to all the three parameters described above, i.e., post-operative hearing threshold, graft uptake and reduction of retraction tympanic membrane in the postoperative period the results were better by 10 $20 \%$ with Tympanoplasty and mastoidectomy in a wet discharging ear. 


\section{Conclusion}

There have been various research papers advocating no difference in results of operating active and inactive ear in chronic otitis media. We studied the advantage of concomitant cortical mastoidectomy in active mucosal COM. We found that results of surgery in terms of hearing threshold were numerically better in the group with Tympanoplasty with mastoidectomy than Tympanoplasty without mastoidectomy by $15 \%$. Similarly graft uptake was better by $15 \%$ and postoperative retraction was less by $10 \%$ in the group with Tympanoplasty with mastoidectomy. The difference was statistically significant with respect to graft uptake but not with respect to hearing improvement and retraction of neotympanic membrane. Surgical improvement of aeration of mastoid, in our opinion, does have added advantage in tympanoplasty in active mucosal chronic suppurative otitis media.

\section{References}

1. Vijayendra H, Rangam Chetty K, Sangeeta R. Comparative study of Tympanoplasty in wet perforation versus totally dry perforation in tubotympanic disease. Indian Journal of Otolaryngology and Head and Neck Surgery 2006; 58(2):165-7

2. Nagle SK, Jagade MV, Gandhi SR, Pawar PV. Comparative study of outcome of type I Tympanoplasty in dry and wet ear. Indian Journal of Otolaryngology and Head and Neck Surgery 2009; 61(2):138-40

3. Hosney S, El Anwar M, Abledelhady. Outcome of myringoplasty in wet and dry Ear. Int Adv Otol. 2014;10(3):256-9

4. Bento RF, Fonseca ACO. A brief history of mastoidectomy. Int Arch Otorhinolaryngol. 2013; 17(2):168-78

5. Rizer FM. Overlay versus underlay tympanoplasty. Part 1: Historical review of literature. Laryngoscope 1997;107:1-23

6. Adkins WY, Benjamin W, Charleston SC. Type 1 tympanoplasty influencing factor. Laryngoscope 1984; 94:916-8

7. Emmett JR. Age as a factor in the success of tympanoplasty: A comparison of the outcomes in the young and old. ENT- Ear Nose and Throat Journal .1999;78:480-3
8. Balyan FR, Serdar, Celikkanat, Aslan A, Taibah A, Russo A, Sanna M. Mastoidectomy in non cholesteatomatous chronic suppurative otitis media: is it necessary ? Otolaryngology Head and Neck Surg. 1997; 177(6):592-5

9. Mishiro Y, Sakagami M, Takahashi Y, Kitahara T, Kajikawa H, Kubo T. Tympanoplasty with and without mastoidectomy for non cholesteatomatous chronic otitis media. European Archives of Oto-rhino-laryngology 2001; 258(1):13-5

10. Krishnan A, Reddy EK, Chandrakiran C, Nalinesha KM, Jagganath PM. Tympanoplasty with and without cortical mastoidectomy : a comparative study. Indian journal of otolaryngology and head and neck surgery 2002; 54(3):195-8

11. Bhatt KV, Naseruddin K, Nagalotimath US, Kumar PR, Hedge JS. Cortical mastoidectomy in quiescent, tubotympanic, chronic otitis media: is it routinely necessary? J Laryngol Otol. 2009; 123(4):383-90

12. Webb BD, Chang CY. Efficacy of Tympanoplasty without mastoidectomy for chronic suppurative otitis media . Arch Otolaryngology head neck surgery 2008;134(11):1155-8

13. Chavan S, Deshmukh S, Kirpan V. Tymapanoplasty with and without cortical mastoidectomy for tubotympanic type of chronic suppurative otitis. Gujarat Journal of Otolaryngology 2011; 8(1):8-10

14. Nayak DR, Balakrishnan R, Hazarika P, Mathew PT. Role of cortical mastoidectomy in the results of myringoplasty for dry tubotympanic disease. Indian Journal of Otology 2003; 9:11-5

15. McGrew BM, Jackson CG, Glasscock ME. Impact of mastoidectomy in simple tympanic membrane perforation repair .Laryngoscope 2004;114(3):506-11

16. Albu S, Babighian G, Trabalzini F. Prognostic factors in tympanoplasty. Am J Otol. 1998; 19(2):136-40

17. Jackler RK, Schindler RA. Role of the mastoid in tympanic membrane reconstruction. Laryngoscope 1984; 94:495-500

18. Wehrs RE, Tulsa OK. Aeration of the middle ear and mastoid in tympanoplasty. Laryngoscope 1981; 91:1463-7

19. Pinar E, Sadullahoglu K, Calli C, Oncel S. Evaluation of prognostic factors and middle ear risk index in tympanoplasty. Otolaryngol Head Neck Surg. 2008;139(3):386-90

20. Albera R, Ferrero V, Lacilla M , Canale A. Tympanic reperforation in myringoplasty: Evaluation of prognostic factors. Ann Otol Rhino laryngol. 2006;115(12):875-9

21. Saha AK, Munsi DM ,Ghosh SN. Evaluation of improvement of hearing in type 1 tympanoplasty and its influencing factors . Indian J Otol Head Neck Surg. 2006; 58(3):253-7. 